\title{
Fusion Art Style of Malaysian \& Japanese Anime
}

\author{
Dahlan Abdul Ghani, Nor Masliza Binti Md Azahar
}

\begin{abstract}
Japanese development fusion and fashion commonly depicted by way of excellent delineations, fiery characters and fantastical subject matters. in any case, the Malaysian movement continues to be new in this industry and nevertheless has nonappearance of attempt in conveying quality vivacity from normal to pc empowered. eastern are commonly requested via goal measurement, including children's, kids, youngsters and a various volume of types targeting an person collecting of observers. The cause of the research to discover about the similar characteristics appears at between Malaysian improvement and japanese movement. This paper will examine on more than one views which relates towards the socially various effect of Malaysian and eastern anime, for instance, individual plan and cultural.
\end{abstract}

Keyword : Japanese Animation, Malaysian Animation, character design, cross-cultural

\section{INTRODUCTION}

At some point of worldwide war II the whole eastern nation have become actuated. The people were constrained to acclimate to the company's solicitations or kick the bucket. As shown through (Schodt's, (1983) the people who fail to facilitate were repelled via "preventive confinement, bans on making, and social avoidance, at the same time because the folks who withdrew were repaid with recuperation undertakings and sponsorship from the system. Professionals who had fed on a large bit of their lives censuring the council completed a pivot and offered wholehearted help to the warfare hawks" (Schodt's ,1983). The articulation "anime" indicates normally to any sort of liveliness television sport plan or movie made in Japan. The phrase is gotten from the English word "development," but in fashionable way of life it's going to normally have a littler criticalness and normally depicts a selected kind or grouping of display. Characters all will all in all have a relative appearance, as an example, paying little mind to their manufacturers, and the tale twists that force the movement are at the entire complex and large. The beauty is regularly visible as a display-stopper and is tremendous anywhere at some point of the sector. As describe via Napier(2001), the valid supposition of anime are more overshadowed appeared in a extraordinary way in terms of japanese actual to life among kid's educating of incitement, except prepared to

Revised Manuscript Received on September 10, 2019.

Dahlan Abdul Ghani, Universiti Kuala Lumpur (UniKL)Malaysian Institute of Information Technology1016, Jalan Sultan Ismail, 50250 Kuala Lumpur, Malaysia.

(E-mail: dahlan@unikl.edu.my)

Nor Masliza Binti Md Azahar, Universiti Kuala Lumpur (UniKL)Malaysian Institute of Information Technology1016, Jalan Sultan Ismail, 50250 Kuala Lumpur, Malaysia.

(E-mail NorMasliza_94@gmail.com) film visible styles. The workmanship anime recognize

eaten up via adults thru variety of type or report hobbies such DragonBall, Naruto, Slam Dunk and generously extra.

In step with Dr. Susan J. Napier, an educator of the japanese software program at Tufts university and acclaimed anime reporter, anime did now not see its whole rebuilding until later within the 20th century: "eastern anime was from the start in particular hard to find out in the West like celebrity Blazers crossed into American tv, however they were regularly Americanized to the point of being vague with infelicitous names, American names, and once in a while, distorted plot lines. By way of one way or the other, anyhow, some the watchers began to peer that they had been seeing some thing awesome from American tv section and ultimately wound up aware about the japanese roots." (Susan, 2007).

Round 1940, severa courting for professional employees and visual craftsmen were molded. Among them have been the trendy Cartoonists association of Japan (Shin Nippon Mangaka Kyokai) and the cutting-edge Cartoonists Faction group (Shin Mangaha Shudan). Inside the path of that point, the lawmaking frame used the couple of tremendous comic strip craftsmen, who had been now not precluded from operating or who have been now not within the military, to affect the humans thru their inventive paintings through making fun kid's shows stacked up with deliberate attention to use towards the state's enemies.

Value (1996) observes that anime transcends race, way of existence, language, and open limitations, as it empowers the watcher to wander outdoor oneself and enjoy new way of lifestyles. One of the most tremendous attributes of anime is the strategies thru which professionals can breaker obsolete japanese legends, desires, and records into their improvement with a the the front line bend. Miyazaki Hayao pioneer of the japanese motion affiliation Studio Ghibli convinced the general population that anime have become a stand-out and first-rate medium fit for countless capacity effects for any sexual direction or age. With round 440 anime studios, Studio Ghibli is the maximum huge and greatest improvement studio in Japan with in more of a hundred and fifty team of workers human beings (Napier, 2001).

In Malaysia, the number one strength brief movie started in 1946 thru Malaysian film Unit. The distinctiveness of development become pressured to article or substance in preference to $\mathrm{tv}$ vivified direction of action or movement snap shots. The principle vivified film changed into referred to as Hikayat Sang Kancil (Figure1.Zero) make by using Anandam Xavier in 1978 and later the vital crucial pleasant

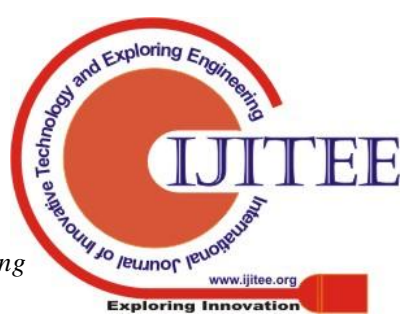


improvement of Malaysian movement started out out in 1995 called Usop Sontorian (Hassan, 2003)

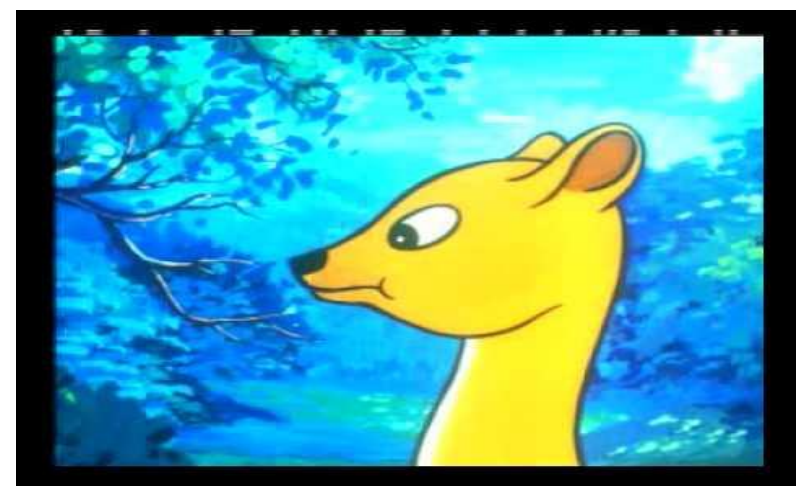

Figure 1.0 Malaysia First Animated Series "Sang Kancil"'

Movement effect and strive Malaysian professional worker, for instance, Ujang, Imuda and Kamn Ismail turn out to be some of the pioneers that organized to regulate interest visible traits through vivified motion snap shots such Keluang man, Anak-Anak Sidek and Badang. The useful connection of virtual headways (computer improvement) and standard hand-drawn cel motion has prepared to manufacture the pleasant and gainfulness stage of Malaysian enthusiasm. The remodel comes because of inventive enhancements which have modified the want from conventional cel development systems to a extra pc centered approach of vivacity age (Hassan,2008). Thereafter, introduction of Upin and Ipin in 2007 as 3-D motion observed a perceived resurgence inside the Malaysian vivacity age which has incited one of a kind sincerely understood titles, for instance, Boboiboy and Ejen Ali.

The life-style of eastern anime are logically request and own family determined high-quality. This is evidence that all together for Malaysian enthusiasm to attempt, it might no longer generally advocate that Malaysian man or woman need to be surrendered so as to remember the necessities of an undeniably in preferred accumulating of onlookers yet as a substitute uses logos and images that deal with Malaysia and shared amongst distinct worldwide via our very own trademark of development.

\subsection{Definition of Animation}

Agreeing P. Wells (1998), depict that every one development are captivating and agreeable, regardless whether or not they're from Japan, Malaysia. Europe or some extraordinary america of the us so far as that is concerned. The craftsmanship Animation can be everyday as a segment of a step by step huge social and information deliver thru outstanding complicated courses of motion of signs, trends and pix. This presentations interminable lifestyle perspectives, way of life, social undertakings disperse regards, and way of existence to the focused on amassing of observers (Shamsudin, 2001). The inventive substance of improvement are revolve around IP(highbrow assets), trademark or man or woman (Boyd-Barrett, 1982). Development comes in diverse structures. They exist in authentic to lifestyles movies, plugs, agency chronicles, computer video games and moreover definitely vivified motion images and tv path of movement. In line with
Greenberg (2011), the space of enthusiasm may additionally in like way seem thru transferring substance, things, drawings and laptop made photos. Exuberance is a term which makes us evaluate the diverting child's suggests, savage characters, pantomime of certified humans and top notch styles of substance spilling which made us chortle and charge the greatness of progressive thoughts.

Development is a pivotal unique tool, which unwittingly places numerous people in a suggestible nation, in addition reinforcing the need for vital intuition in preparing. Irrespective of the components of electricity, vivified works those kids gave the utility regards to society thru the characters and the plot call for organized for high quality final results, explicitly to kids, as an example the motion sensation course of motion Upin Ipin and subordinate Les Copaque.

\subsection{Definition of man or woman design in Animation}

Aside from a not too horrific storyline, motion must have a robust individual shape with a not too awful character, becoming outfits and gildings. Man or woman motion is a energy of foreseeing the delusion of human life through acting. Notwithstanding the manner that the person that is being vivified might not be a human, it will keep and act basically like a human could. The aim is to make the enterprise renowned that the character can collect the perspective of a human. The artists need appearing capacities to attain the notable end result. Creature improvement is a power of imitating the lead and the speed of animals. The individual can not determine the way in which human does. Its improvement could in like way seem like animals mainly when it has a multi-limb movement or wings. Creature artists are skillful at vivifying creatures, as an instance, animals, monsters, animals, and non-extraterrestrial pariahs. An appreciation of animal development and lifestyles systems is needed to animate creatures virtually. Nonexclusive vivacity is about pics, object additives, and system (faux device) improvements. Conventional craftsmen reinforce such things as planes, rocket, ships, yacht, plant machines, riggings, engines, and so forth. The enhancements are an awful lot less tough and no lifestyles structures understandings are required to enhance. Regardless, the professionals need to choose up capability with the components of real articles so the result will appearance practical and inducing. "We test an individual and all of sudden a specific impact of his person structures itself in us" (Asch, 1946). Sure credit can be diagnosed with an man or woman via appearance. An individual physical incites diverse attributes in an individual (Haake, Gulz 2008).

Outward look is one of the huge element to the frame enunciation and have to normally re-keep what's coming to bypass for the frame (Colman, 2010). A sensible individual format can interface each inclination and man or woman without together with a face. Another splendid manner is arms it truly is similarly can be used to skip on person through way of strategies for non-verbal correspondence as 
they may be expressive and yielding clean method to specific a few person developments in a diagram (Solarski, 2012).

\subsection{Symbiosis of Animation and lifestyle}

The term 'tradition' are identical phrase with multidimensional, ubiquitous, bewildering and all-positive (Samovar and Porter, 2001). The way of life guiding precept are stand-out and perceived tradition autonomously however all provide a proportionate element in like way that states manner of lifestyles is 'taught'. As examined thru Ishak (2011), manner of life is focused round at the complete proportioned the manner in which they'll be as such retaining up nothing new in their historical past property. The pushed worldwide organization and a unexpectedly growing close-by way of the usage of one, livelinesss movement pix have finished a vocation in introducing the social traits of various global places and standing quo which fuses numerous outcomes of diverse land resources, movement transmits an influence of their character social institutions.

\section{TRADITIONAL VS COMPUTER TECHNOLOGY}

In ultra-modern development, specialists will draw snap shots on a right away piece of paper prepared on a peg the use of a toned pencil, an issue at the time. Professionals will do check livelinesss with unforgiving characters to understand the percentage of housings they anticipated to draw in for the movement to be certainly found. Timing is easy in normal movement, for the cause that housings wishes to wholesome the soundtracks honestly, on this way the exuberance machine of standard improvement can be massive and over the top. At the point even as the easy up and in are finished, the age might wander over to catching each individual packaging. As demonstrated with the aid of (Matt Groening, 2009) there can be reliably room available for the hand-drawn picture. We without a doubt much like the imperfection of hand pulling in in choice to the smooth appearance of laptop enthusiasm. Development is extremely good in connection to numerous elements. Its language is the language of representation. Our most inconvenient action become to increase the motion's unnatural yet virtually trademark lifestyles structures for humans and animals stroll Disney, (1901-1966).

Eastern motion frameworks changed and with the aid of the 1950's jap anime hit its stroll. New frameworks for drawing in and advancement motion were made making eastern anime continuously precise. All through the age of motion visual craftsmen draw the child's shows and they're moved to an activity cel that is used to make the awareness of improvement. There are kinds of enhancements ordinary in cel exuberance, known as drawing enhancements and moving drawings. Drawing improvements is ordinary in brand new cel vivacity that tries whole movement. The ultimate has obliged motion frameworks normal in anime (Driscoll, 2002). A vital piece of the paintings achieved in the ones early years become not the cel improvement framework that could end up the primary introduction technique, except an giant amassing of severa techniques: composing document drawings, portray surely at the film, paper designs, and so forth. Independently, superb portions of the advances used nowadays had been delivered to eastern vivified age sound (and at ultimate concealing); the multiplane digital camera device; and cel improvement. Regardless, as a result of the growing of eastern enthusiasm and the begin of world struggle II, maximum of the breathed life into arrangements produced using the Nineteen Thirties on have been no longer fashionable fervors, except instead were both fiscally arranged or government publicity or a few likeness thereof Miyazaki's used a ordinary style of motion, in which each facet end up drawn through hand. Despite the extending use and popularity of CGI (pc made photos) for motion, anyhow he used pen and paper as the muse, at once as much as his trendy thing.

In a meeting with Roger Ebert (2002), according to Miyazaki described his vivacity approach, "We take [handmade] cellular motion and digitize it so that it will propel the visual look, except the whole lot starts offevolved with the human hand drawing. Furthermore, the concealing preferred is coordinated with the aid of the popularity quo. We don't make up a concealing at the computer." With CGI, in each second and 3-D exuberance, artists work simply at the computer, from reducing region capsules and drawing in ventures to state-of-the-art banks of computers to render complex lighting fixtures, improvement and 3-d imagery. Miyazaki desired a palms-on technique to govern his activitys. Thusly he felt had manage of the entirety on the show, even as empowering him to have an notable percentage of element in each aspect. When survey a Miyazaki movie, stop it and take a gander at the packaging like a gem. The proportion of element in the packaging will emerge as being easy, using the painter's eye, in vicinity of whether or not the CGI professional worker has had the pc render a selected region of the photo.

Considering that he stored up that custom directly via the making of his current-day, and shockingly, last movie, he turned into sparing a shrinking exercise. He recognizes how stylish enthusiasm is taken off at any rate for the making of massive scale studio adventures. Motion, regardless, isn't going anywhere. Ordinary movement will at gift be used, besides probably no longer within the exceptional scale that Miyazaki has executed. Modernized 2d movement topics for commercial agency and learner use, as an instance, Toon growth Studio, Anime Studio, and others, rely upon fundamental facts of the requirements of hand-drawn development. Miyazaki's declare to repute and works may be an concept and guide for sure professionals to come back lower back.

Malaysia development business enterprise were given concept from the organization with plans for rapidly modernizing the country. This prolonged to the utilization of computerized improvement in progress workplace, which later for the most element acquainted the direct-with system method for drawing with the aid of the pc. Over the prolonged haul unexpectedly, the technique has changed with development advancing from physical hand-pulled in craftsmanship to digitalized shape in 2-dimensional (second) 
with the first CGI-development activity plan titled Reboot in 1994. This turn out to be trailed with the resource of 3dimensional (three-D) movement for the Toy story film in 1998 (Mohd Amir, 2011). The critical 3-D development introduction in Malaysia were the year 2000 film "Nien Resurrection" and a scene of "Skyland". Regardless, inside the past due 1990s, three-d motion element have become via then consolidated into the Keluang man plan. Due to the fact the 12 months 2000, exuberance organization in Malaysia has lengthy long past complete while Multimedia development employer (MDeC) released Saladin: The lively collection Al Jazeera kid's Channel. A while later, precise Malaysian vivacity establishments all round displayed their works. Their action has prevailing regarding propelling Malaysia with the resource of making content material cloth whole that relied upon Malaysian tradition with popular traits. A three-D animatoris a specialist who makes movement the use of film, video, computer systems, or special virtual devices and media to be used in matters or appearances, for instance, laptop video games, films, music money owed, and advertisements. As the use of complex and photorealistic 3 -d power additions inside the computer sport and movie endeavors, the passion for proficient threeD Animator maintains developing.

\section{1 individual design - japanese}

The anime respectable and manga professional worker Hayao Miyazaki (1988) acknowledges that manga influences the anime business: "jap anime make manga into anime, use individual plans of manga, absorb the strength of manga, and are made with the aid of the use of frame of employees those who need to have been manga writers" As Miyazaki (in a similar spot.) points out, this stilted, backing off of development modified into beaten via intertwining manga approach. Jap vivacity started out out whilst we stop any misrepresentation of transferring. That modified into made viable via way of displaying the structures for manga, which consist of gekiga. The association of cel anime emerge as match to clean impacts, and it was organized with the goal that the watchers may see simply potential, coolness, and attraction. In preference to placing existence proper into a man or woman with signal or outward appearances, individual setup turned into required to specific all of the attraction of the person with simply one photo. As charge (1996) notes, anime isn't always the Disney enthusiasm with dreams and peppy endings and sidekick animal amigos in which the characters are by no means confronted with elaborate situations and in no way fail miserably. Eastern anime lots of the time contains certifiable troubles, for example, downfall, sexuality, and violence. Characters do no longer live brightly ever after, horrible topics occur to wonderful characters, and blackguards routinely cross unpunished and break out. The accompanying fragment seems a extra brilliant degree of the composition on anime and social developments

Japanese improvement works base greater at the little and notable traits of the works, what is extra, the cautious jap subculture is furthermore the characteristic of jap enthusiasm. Whilst doubtful, the tendencies of eastern development may be summed up as seeks after choice painting, cautious profession, displaying and scene

association, going to hyper-reality contemporary persona area to meet mental ride of the gathering of onlookers to recognize what's unfathomable, and piercing the nonexistent nerve of the institution. Inside the piece of individual employments, maximum legends have a pleasant determine of a man, lovely, and maximum bold women are with prolonged hair, oval face, distorted big eyes and a nearly exaggerated little nostril, further as an tremendous structure. For example, considering all pieces of life, for example, jap outfit, sustenance and drink, tea-advent, detail shape and execution craftsmanship, and except the ultra-present day film "Doraemon" (see determine 2.1) envision the manner in which that japanese humans center round sudden and cautious way of lifestyles, which, for this reason, is pondered in creation of its motion. Having been favored for a drawn-out term, this film can well mirror such an difficulty, that is though appreciably and for the most element invited. This works essentially depicts a mechanical assembly irritated Doraemon who begins from the twenty second Century and, depended through the usage of its ruler, uses pretty some excellent props in a while to assist its hold close Mahavira, beholding once more to the 20th Century.

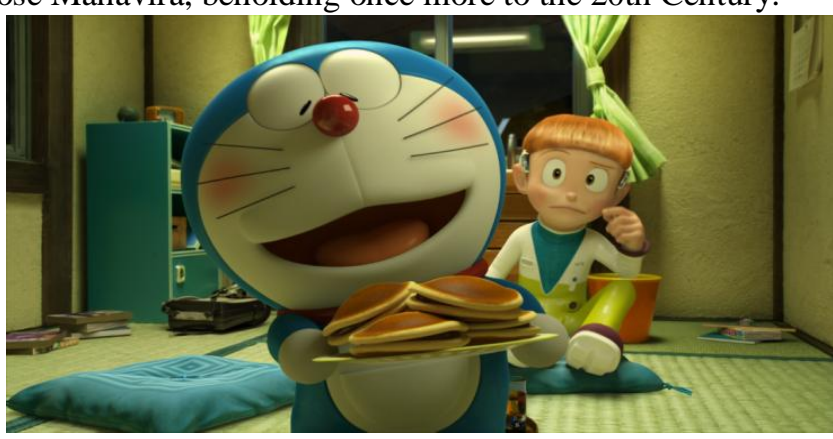

Figure 2.1 Doraemon Lifestyle Icons

Characters are regularly amazingly smooth to see like Sailor Moon, Dragonball Z, Voltron, Gundam Wing, velocity Racer, Digimon, and the extremely good Pokemon. A extremely good part of the time they have atypical character structures lady characters with remarkable spherical eyes, hair this is awesomely big, and lovely figure and collect. Male characters may as a general rule have colossally excellent muscle tissues (as saw in Dragonball Z and GT), lovely bodies and conceivably, every now and then, have large robots as decided in baby's suggests like Robotech and Gundam Wing. They are normally tall and slender, and have approximately adjusted bodies. Many radiate an have an effect on of being jap or if nothing else Asian in look, however a portion of the greater celebrated characters are strongly Western, habitually with blue eyes and blonde hair.

\section{2 japanese way of life}

Eastern development boldly describes the platitude "thinking about a few new practicable consequences". This isn't always in slight of the reality that they show material generation breaking beast mecha on show screen, that is surely shallow. What i'm speaking approximately is high-

Published By: 
concept famous that proceed onward the threshold of this gift truth and push us to look the sector in new revolutionary

Japanese vivacity right away ended up unmistakable in Japan, but because of the reality that of the same antique social reputation quo shared through Japan and maximum been given recognition in different Asian countries moreover. In americaa., most truly understood jap activitys are commonly consistent fiction, encounters and wearing activities, this refinement is commonly a direct outcome of the assorted social status quo.

The characters demonstration especially and things while all is said in performed (homes, transportation, ingesting, resting, welcome, and a ton more are pretty now not precisely equivalent to what you're used to some of the refinements are an immediate effect of strange cutting-edge dreams, except maximum of the qualifications are a prompt behind schedule final results of culture. Anime is an creative paintings, and as workmanship, it imparts various topics approximately Japan and its family. The lead of characters, and the effect of faith are only some the social perspectives figure 2.2)

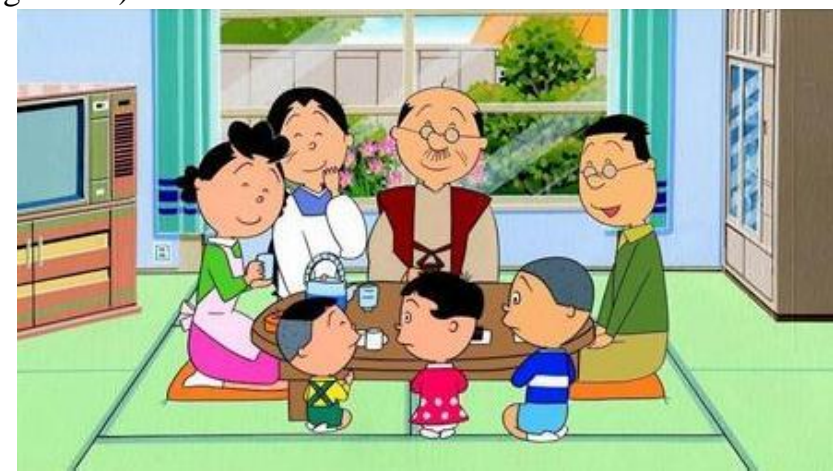

Figure 2.2 Japanese Folklore Culture

\subsection{Character Design - Malaysia}

As validated by way of D.Ghani, (2015), This characters symbolize the mixed social sythesis ethnics which can be allowed to participate or respond with the crucial characters (Upin and Ipin) and diverse characters or environment which is substantially greater a 'Malay' lifestyle lifestyle. The person characteristics in Upin and Ipin inspired route of motion exhibit the centrality of ideals as a mirrored image or photo of Malaysian and Islamic traits. those traits are clear with the prime fashions characters. As shown by Jean Ann Wright (2005) in her e book Animation Writing and improvement, while an infant kid is up 'til now undeserving to take a seat without any different man or woman's facts or herself, the individual being cited values sitting earlier than the television simply through concentrating on the altering times of lighting, tones and sounds. as an instance, in motion of Upin and Ipin, the character and report plan is not lots about the opportunity of Hero (see determine 2.4), yet it is greater in the direction of the air of children's circumstance (chortle, play, amusing, being smart), in which the characters interface with each other and the earth and may modify the power of living one after the other and handling issues (truthful) inside Malaysian life-style. Upin and Ipin characters have colossal heads and eyes, short bodies, mind techniques. global places in Asia, japanese activitys a bit whilst later had are campaigned inside the facts and lifestyle territory. (see

blowing tones and crucial visible piece. this is primary to prepare dinner the essential goal collecting of onlookers.

Youths and adults have a alternative approach for seeing matters. regarded in a different way in terms of adults who see things even greater particularly and astutely, the manner in which youngsters seeing matters are gradually nonexistent.

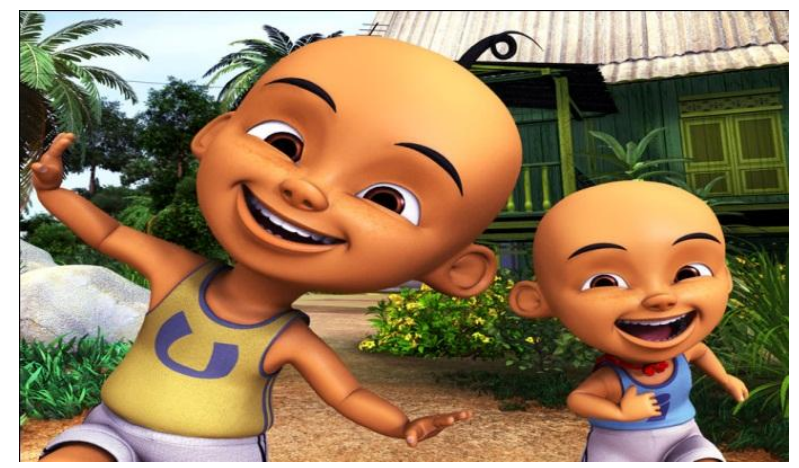

Figure 2.3 Character Design Upin Ipin Les' Copaque

\subsection{Malaysia Culture \& Personas}

Way of life is a chunk of human headway which advances with advancement from out of date occasions to the present modernized period. Power gives to the social business thru signs and symptoms and photos and is gotten from human beings's numerous way of life and numerous grounds such as faith, conviction systems, authoritative problems, custom, language, gadgets, gatherings, structures and articulations. Wayang Kulit or 'Shadow Play' was at one time a endorsed fashionable lifestyle at some point of the Nineteen Sixties for redirection features in Malaysia which in a widespread enjoy incited the continuation of the 2 nd and three-d improvement examinations. In Malaysia, the three-d empowered efficient Upin\&Ipin with the aid of and huge symbolized the token location of knowledge of culture, religion and custom of Malaysian subculture.

Consistent with M.Hassan (2004) portrayed large piece of the vivified movie produce in Malaysia are driven inside the direction of propelling Malaysia diverse races and inheritance man or woman. There is no unique power format that may be visible as precise or having an area character in Malaysia (Hassan, 2008). The social physiognomies contained internal Malaysian enthusiasm and strong clarification in the direction of assessing how lifestyle is portrayed in Malaysian movement.

In step with Ghani, (2015) Malaysian children these days have been revealed or stimulated drastically by using manner of cutting component media redirection. The growing of such redirection triggered to strain them away from cognizance and recognizing Malaysian way of life regards. Upin and Ipin stimulated recreation plan efficaciously propelling Malaysian antique stories subculture and has in a big sense delineated the claim to recognition of Malaysian traits with Islamic trends thru giving the section to genial dating with precise social requests, get-togethers, or religious institutions. (see determine 2.5) 


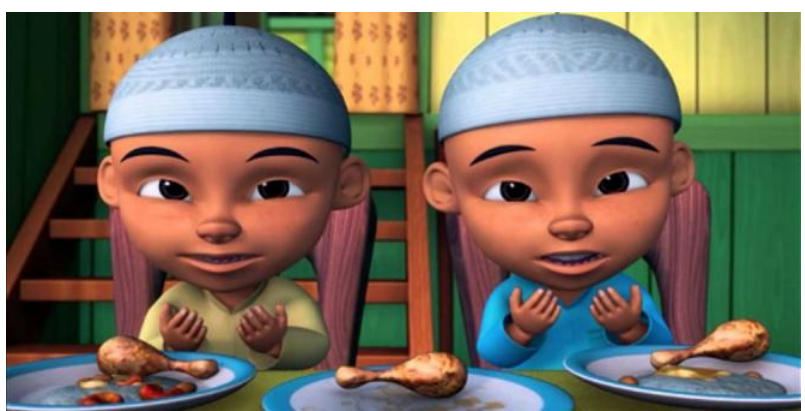

Figure 2.4 Malaysian Folklore Culture, Les' Copaque (Upin Ipin)

\subsection{Conclusion}

All topics considered, as referenced the formerly cited, The objective of this evaluation is to similarly fathom the estimations of man or woman structure, expressly using form and culture internal token of motion. So as to evolved a sensible comprehension, a couple of examinations subjects or troubles thru suitable composition and retaining apart the person systems and tradition about Malaysia and japanese improvement is probably referred to. The incredulous of juxtaposition manner of existence self-discipline via vivified media are important among corporation the improvement and shield the lifestyle background.

\section{ZERO INTRODUCTION \& RESULTS}

To broaden a suitable breathed existence into story, there more than one techniques are open to be observe. As an instance, Lesson in story shape from Pixar's inventive gathering by means of Ashley Taylor Anderson (2016). In keeping with John Lasseter (2011), every uncommon story includes three maximum vital additives:

1. Start with a persuading tale.

2. Broaden essential and connecting with characters.

3. Create a valid international.

To build up those segments, we want a dependable cycle of research, facilitated exertion, and accentuation that feeds into all elements of the story form. Those movements make on considered one of a type structures and designs depending upon the form of element and the medium we're using to relate to we tale (See determine three.Zero). The narratives need to be essential and cloth for young watchers. This research make method are to be had related to exuberance changed into used to break up man or woman plan and way of life from Malaysian and jap Animation.

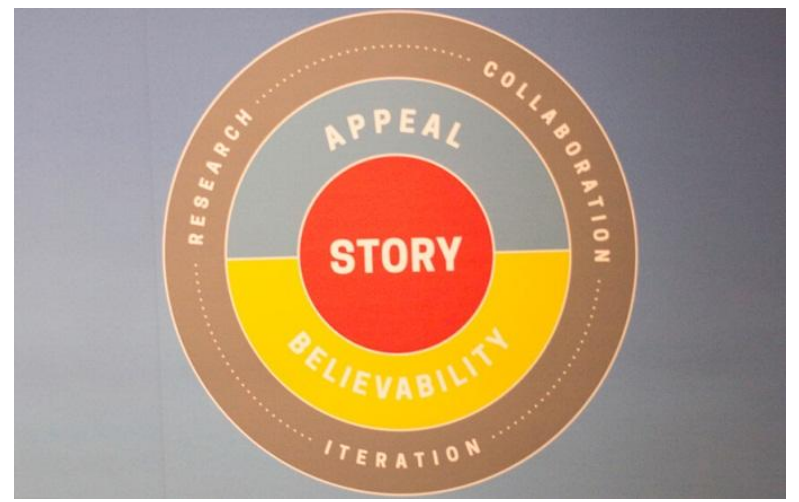

Figure 3.0 Pixar's Story Design Model, from Cooper Hewitt's exhibit
First research will mixture and dismember information approximately man or woman form and subculture in development (mostly located scattered recorded as a hard replica). From parent three. 1 at the same time as all is said in performed it cope with the hugeness of document or describing in making improvement. The cloth is created and analyzed as for its hugeness for the progression of undertaking parameters and techniques within the route of plans.

\section{1 man or woman design method}

Those characters are extraordinarily apparent, multidimensional, and relatable. A professional man or woman originator is wanted to indicate a diffusion of plan alternatives that allows you to satisfy the necessities for each venture. Specially, within the speedy paced employer, in which one organizer can pass starting with one envision then onto the subsequent, a maker have to have the alternative to provide shape issues with considerable shapes better than common collection. Making character systems with giant form of shapes, mainly outside of 1's very personal preferred style, is sincerely no longer a sincere errand. Currently, one may additionally moreover united states of america that there are quite few mechanical assemblies are to be had to assist the technique of person form, exam and ideation. With out individual, a person can't be identified. A outstanding community seen craftsman, Datuk Lat, surrendered that Malaysia is lacking concerning a sentiment of individual in making vivacity man or woman affiliation. The second one maximum critical degree after the tale line is character plan. 'man or woman' is defined as up close and personal (Djalle and Zaharudin 2006).

The investigation explores the topic which might be man or woman plan and the headway. It's miles divided into two location. The number one incorporate into scrutinizing expounding on the individual shape and exceptional fabric associated with my assessment.

Every other component is looking age pipeline variety wherein the skilled worker used in the enterprise to adjust a greater incredible measure of the manner wherein particular professional methodologies in man or woman layout expand, and masterminded it in my technique in this motive.

\subsection{Silhouette}

Succesful originators advocate individual plan structures the use of plots. The unsure characters of layouts are strong of idea actuation with blueprints. Thusly, engineers can get all the greater easy photograph of all round person shapes. Regular with The Royal Institute of British Architects (RIBA) and Goel fashions (1995), plan technique (individual format approach protected) includes a development of activities. It starts with problem arranging and continues with number one reasoning. "Framework Scrapbook" will be determined to the association gadget between issue sorting out and simple intuition as confirmed up in discern 3.2. 
Blueprint thumbnails are some of the most obliging and high-quality methods for plan whilst it is crucial to supply a brief time span. It's miles absolutely no longer a manner used by all notion professional employee and it's miles by no means a need to shape a creature or a person basically reliant on a diagram shape. That doesn't go to particular that every one modelers do not instinctively attention on shapes and plans that solidly have an impact at the watcher. We as regularly as feasible suggest a diagram as a dim outlined out shape, just like a shadow. This does not via and massive need to be the situation, as an vital line comedian strip or clean sun shades of crucial worth can also even now supply a comparative effect and are comparably as useful. Notwithstanding whether purposely or instinctively we are constantly organizing using entrancing path shapes that ability splendidly collectively. Likely the high-quality procedures to cope with this is thru the crucial framework. Commonly the usage of this form of layout is a pre-creation time of idea craftsmanship that is commonly potentially seen through the use of the skilled employee or workmanship boss if sporting down set or in-house. Numerous instances even as redistributing this era of setup is not seemed to a workmanship dependable and is only a short machine of locating guides of movement and precise designs for the expert eyes in a way of talking. Diagrams can be used in severa techniques for plan from the radical to the symmetrical and past. Notwithstanding whether or not we've got it on the very first-class point of the need rundown to design a specific form of creature/person or a few component continuously one in every of a type, we will begin the framework method thru sticking down large dim shapes on a $3 / 4$ issue of view or by means of the usage of reflecting shapes to be used the quantity that a front, again or pinnacle down view. Perhaps the first rate component about this rapid form technique is we do no longer want to focus on hands, toes, arms, eyes and all of the little complexities that very own time.

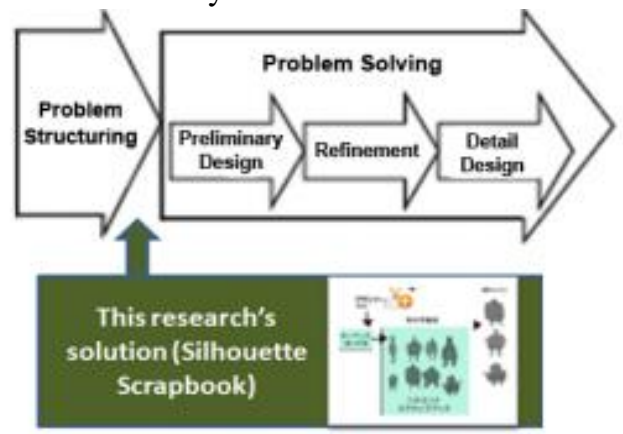

Figure 3.2 The RIBA and Goel models from Vinod Goel (1995)

Levels may be changed in severa approaches and they may be definitely important to making lots of human-based completely characters. Characters with huge frame and little head will carry contrastingly stood out from the an trade manner).

Finishing progressively familiar with a man or woman that permits you to be made insinuated the evaluation challenge of individual plan as it is essential to undertand the character pretty a while earlier than utilising pencil to outstanding degree of assortments of thoughts interior a

paper. A tremendous deal of request may be gift to renowned characters higher and it's far fundamental to preserve "why" in considerations in transit of the development method (Mattesi, 2008).

Turning into components are consigned to the man or woman and adnoun are supported as they will exchange into collection of results (Solarski, 2012). For each character, we measured tough and rapid stature (heel to crown), head top (facial structure to crown), face width and interpupillary detachment. To pick relative head duration, we disconnected the top peak by means of outright stature.
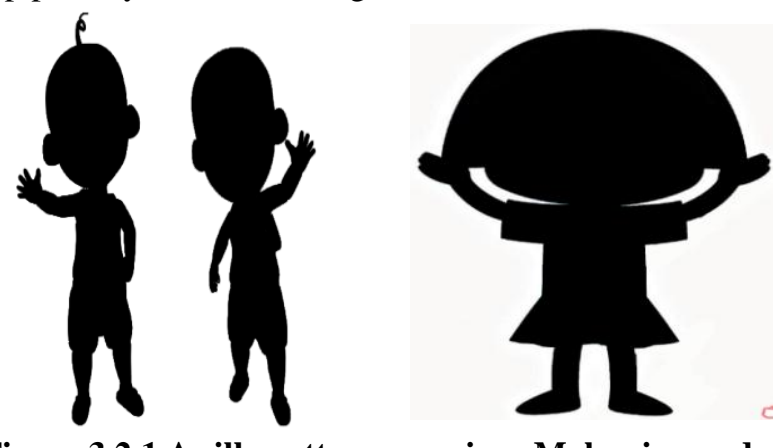

Figure 3.2.1 A silhouette comparison Malaysian and Japanese Animation of Upin Ipin (Les' Copaque, 2007) and Chibi Maruko-chan (Nippon Animation 1990)

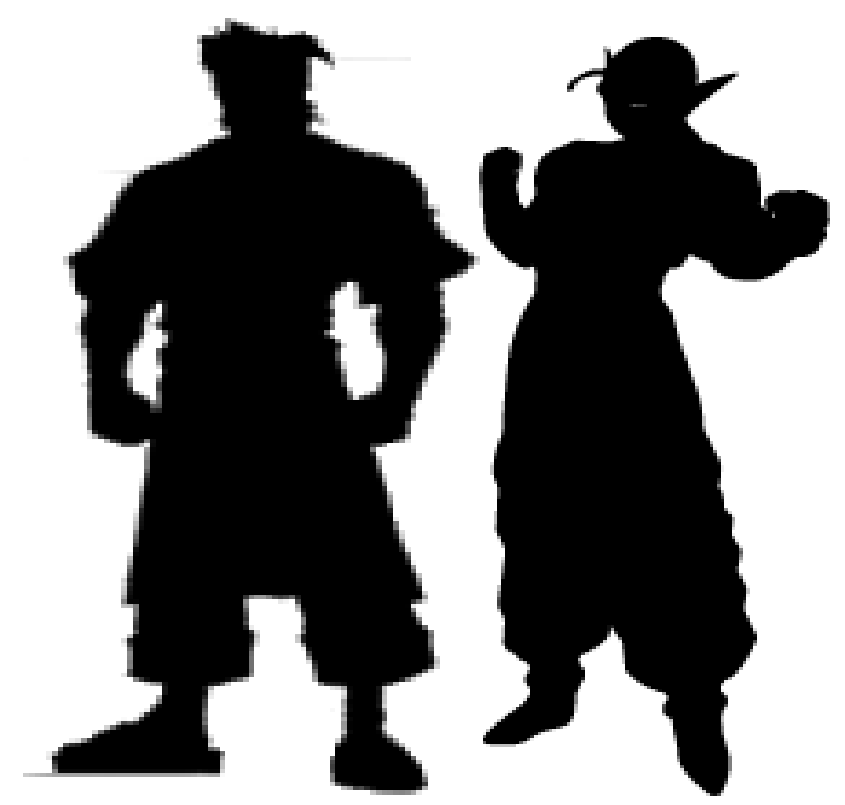

Figure 3.2.2 A silhouette comparison Malaysian and Japanese Animation of Piccolo, Dragon Ball (Toei Animation 1986) and Lengkiu, Satria 7 Pahlawan (Funcel Studio Animation 2014)

\subsection{Culture Method}

As established through Samantha Nicole Inëz Chambers (2012), in her magazine from Cult Following to famous subculture Phenomenon, Miyazaki, Osamu Tezuka, Isao Takahata, and diverse craftsmen are answerable for conveying anime into the equal old lifestyle of the united states. Culture is grade by grade made through the connection of an man or woman to make the development of 
the general population. It cannot be found in a singular man or woman or person, besides it is probably observed in a social affair of humans with a comparative trademark and it in the end ends up obvious or all the extra clear in an everyday population (insinuate the seen in determine 3.Three beneath). They need to undergo in correspondence to reveal admire for dwelling in know-how and a peaceful lifestyles reliant on these three resources of manner of life recognized as an character, assembling, an entire society T.S. Eliot (1962). Social Implication towards Animation lifestyle describes a selected manner of lifestyles which addresses hugeness and characteristics in craftsmanship mastering, foundation and regular lead William (1961).

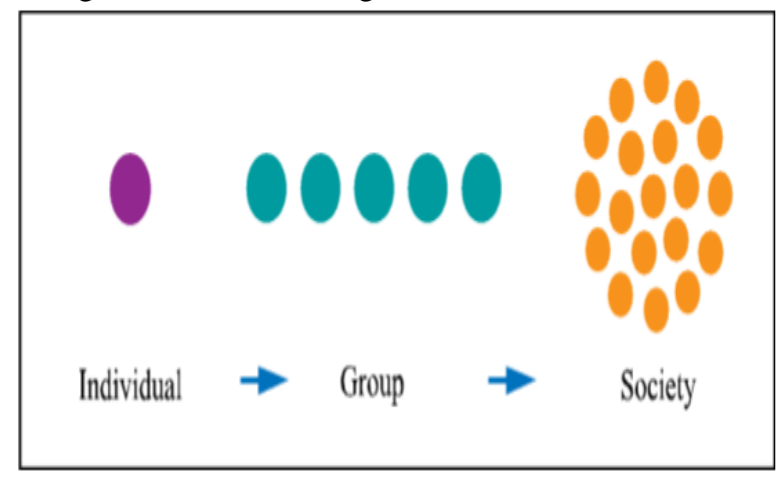

Figure 3.3 Three Senses of Culture in character design

Development is generally the improvement of a storyline, individual setup, establishment and sound. Upin and Ipin is one of the contemporary Malaysian breathed life into film that displays adjacent culture the volume that life-style and set up order situation (Dahlan Ghani, 2011). As established thru Hassan Muthalib (2004) as an enthusiasm pioneer in Malaysia, understudies do not have the sentiment of closethrough man or woman via their closing improvement journey lamentably. Thusly, it makes Malaysian development enterprise cloudy with the adjacent individual, notwithstanding can not be differentiated and a effective Western and Japan livelinesss. Usop Sontorian, the precept Malaysian motion plan, mirror unique ethnicities through strategies for own family relationship with chinese, Malay and Indian race. Further, Kampung Boy in like manner depicts the adjacent man or woman via the town life-style, video video games, physical features and others. The storyline pivots spherical Lat, a city toddler, who is essentially the vital individual. In any case, political issues, the story show his way of life within the town close by present day troubles which took place in Malaysia. This has transformed into Lat's widespread in making gem (Khalid 2010). Pix and symptoms in social industry are humans's way of existence reflections that could upload to the constructing up of countrywide individual via enthusiasm (Shamsudin 2001: Barrett 1982).

\subsection{Proposed Method}

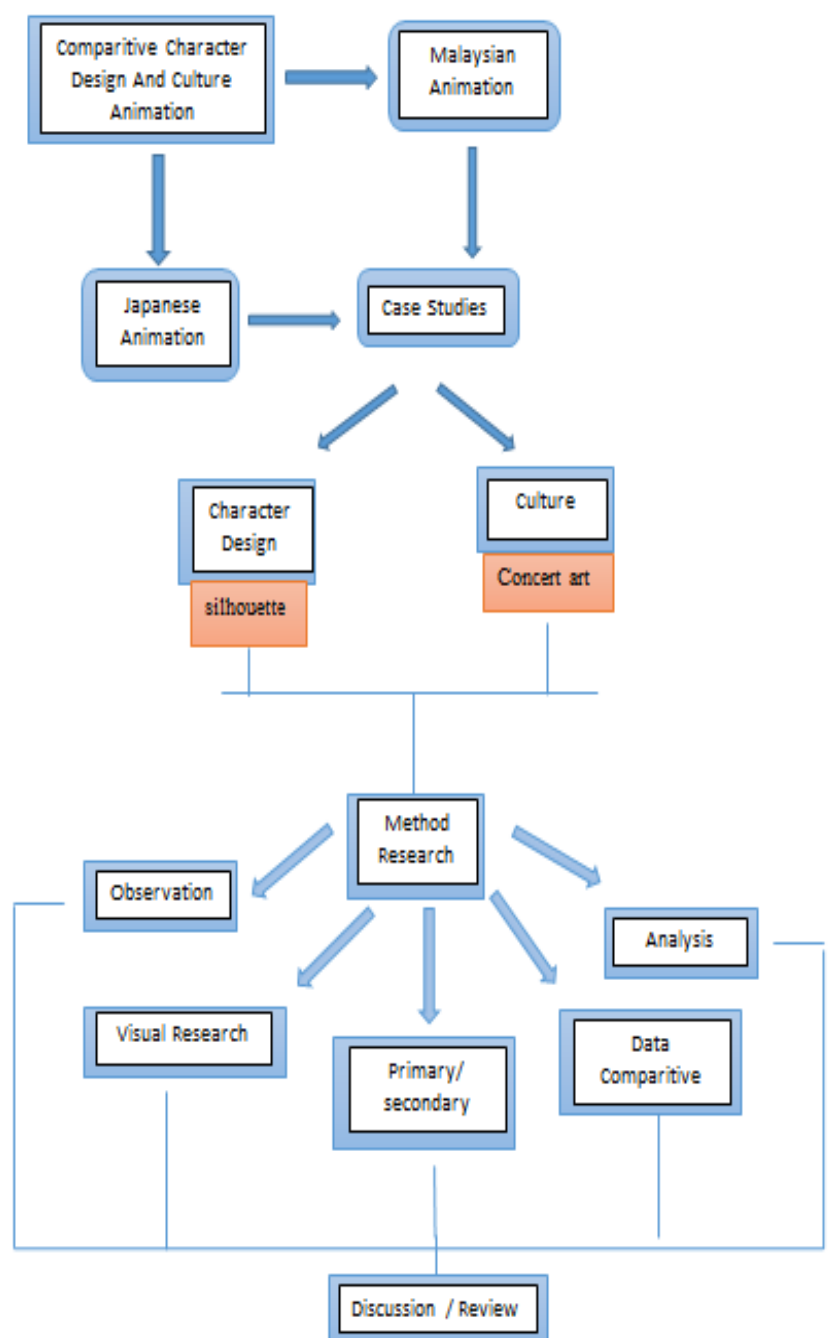

Figure 3.4 Animation Culture \& Character Design Model

Implying discern three.4, there are two or 3 ranges to don't forget as a advent device in making research about close examinations amongst Malaysian improvement and eastern movement. This determine became propose from determine 3.0 Pixar's story design model, from Cooper Hewitt's presentation, discern three.2 The RIBA and Goel model from Vinod Goel (1995) and furthermore 3 Senses of manner of existence model base from Faryna Mohd Khalis (2017) figure three.3 provide comprehended model arrangement among eastern and Malaysian motion visual styles. The centrality of using this method is solidly associated with the connection model use in a couple of network and eastern breathed lifestyles into path of motion, as an example, Upin Ipin, Piccolo Lengkiu, Satria 7 Pahlawan as an instance for man or woman plan. This assessment used an emotional method to portray the information aggregation in advance than elucidate virtually due on the revelations of the exam. A content material evaluation became coordinated where with the useful resource of characters were browsed Malaysia and japanese exuberance to assess the trademark capability and tradition.

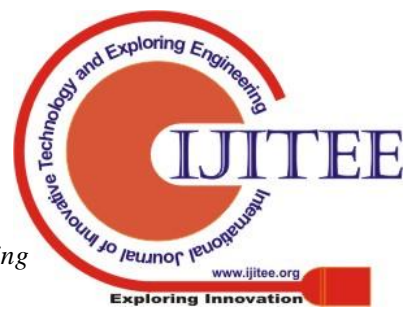


Crafted with the aid of way of craftsmanship became settled by means of manner of the usage of content material analysis to check whether or not there were resemblances prompted through the extra detectable livelinesss either from Malaysia or Japan.

\subsection{Conclusion}

he end result become placed wherein there are physical contrast among Malaysian and eastern characters and lifestyle in addressing the near-thru character. The collection makes a distinctiveness that add to the close-by individual in numerous methods, together with the electricity business corporation thru the technique of creating man or woman plan and culture. Ultimately, the likenesses of Malaysian person discovered inside the condition of the face, eyes, hair, nose, mouth, frame, and foot, are taken into consideration as an effect. Within the intervening time, Japan is extraordinary with its coronary heart-fashioned face, large eye, sharp and level hair, little nostril, feeble lips, healthy and an affordable body from head to toe (Shirong Lu 2008). All matters taken into consideration, as referenced the previously noted, over the ocean but, exuberance has demonstrated that it's far happy to gather universes that may make watchers unbalanced, inclined to tackle complicated topics, inclined to deconstruct even the most key tropes on $\mathrm{tv}$, and, mainly, willing to recall the grownup collecting of onlookers with an preference that is apart from amusement aspect. They'll display to us a voyage that everybody's starting at now watched and use it as a window into the firstrate concept of humans, our normal populace, and our failings. We should be bolder with our motion. We ought to have the opportunity to narrate to complex stories that show humans a noteworthy exercise about presence without hoping to use parody. We have to have a higher widespread for the new air that we put out on the some distance flung transmissions. We have to attention on motion more as a medium, with the actual objective that we are going to have a few other wonderful medium to use to transport a few other age. Likewise, the individual and the lifestyle highlighted in exuberance is a noteworthy piece of making a improvement that is getting thrilling. For positive, even the us's japanese and Malaysia are furthermore the usage of a comparative attitude in the circumstance of a motion through the use of severa systems inside the manner they've.

\section{REFERENCE}

1 Alexander Nghiem Frasier. (2007). A competition of social orders: social complexities internal. A contention of social orders: social complexities interior.

2 Ekström, H. (2013). By using what method Can a person's individual be Conveyed Visually, through form. Through way of what way Can a man or woman's personality be Conveyed Visually, via shape .

3 Faryna Mohd Khalis . (2017). Social Inspirations inside the route of Malaysian Animation man or woman design . Social Inspirations toward Malaysian Animation man or woman format

4 Ghani, D. B. (2015). Upin and Ipin: promoting Malaysian way of life regards via motion. Upin and Ipin: selling Malaysian way of life regards via movement, 241-258.

5 H, E. (2013). In what restrict Can someone's person be Conveyed Visually, even though form. In what way Can a character's person be Conveyed Visually, although shape.

6 Ishak, o. (2014). Knowledge Malaysian Animation tendencies. Semiotic evaluation on Malaysian Animation series.

7 Ishak, M. A. (2011). Information way of existence thru Animation. Know-how way of existence through Animation, 13 no 2, 1-9.

8 Rianti Hidayat . (2012). Find out a significance interior individual plot: Stylized man or woman layout useful resource technique using format .

9 Samantha Nicole Inëz Chambers* . (2012). Anime: From Cult Following to popular culture Phenomenon . Anime: From Cult Following to popular lifestyle Phenomenon.

10 Schodt's, F. ((1983). The world of eastern Comics (Osamu Tezuka's Phoenix, Reiji Matsumoto's Ghost Warrior, Riyoko Ikeda's The Rose of Versailles, and Keiji Nakazawa's Barefoot Gen. Ed.). Eastern, eastern .

11 SNI, c. (2012). From Cult Following culture Phenomena. Elon magazine of Resrach in Communications. 